\title{
Evaluation of Harpoon Tips for Debris Capture
}

\author{
By Takahiko MAtAkI, ${ }^{1)}$ Yasuhiro AKAhoshI, ${ }^{1)}$ Takao KourA, ${ }^{1)}$ Yukihito KitAzAwA, ${ }^{2)}$ Kazuo SHIMAmURA, ${ }^{2)}$ \\ Taku IzumiYama, ${ }^{2)}$ Kozue Hashimoto, ${ }^{2)}$ Satomi Kawamoto, ${ }^{3)}$ Jun-ichi Aoyama ${ }^{3)}$ and Tadao FukUtA ${ }^{4)}$ \\ ${ }^{1)}$ Department of Mechanical and Control Engineering, Kyusyu Institute of Technology, Fukuoka, Japan \\ ${ }^{2)}$ IHI Corporation, Tokyo, Japan \\ ${ }^{3)}$ Research and Development Directorate, JAXA, Chofu, Japan \\ ${ }^{4)}$ Department of Systems Engineering, Okayama Prefectural University, Okayama, Japan
}

(Received July 31st, 2015)

The Japan Aerospace Exploration Agency (JAXA) is developing an active debris-removing satellite using an electro-dynamic tether (EDT) system. A harpoon system is a promising strategy for attachment of the EDT to target debris. This paper investigates the properties of different harpoon tips, and their effect on perforation. Using a powder gun, six types of projectiles (flat, flat 3, cone, puncher 0, puncher 2 and puncher 4) were impacted upon target plates and evaluated in terms of their velocity, kinetic energy and penetration length. The target was a $3 \mathrm{~mm}$ thick plate of 2024-T3 aluminum alloy which replicated the surface of an H-IIA second stage. From the experiments, it was found that puncher 2 was the most effective for perforation.

Key Words: Harpoon, Debris-capture, Debris-removal, EDT

\section{Nomenclature}

$\begin{array}{lll}V & : & \text { velocity } \\ W & : & \text { penetrator mass } \\ L & : & \text { penetrator length } \\ D & : & \text { penetrator diameter } \\ T & : & \text { target thickness } \\ \rho & : & \text { target material density } \\ \theta & : & \text { incidence angle } \\ M & : & \text { modification factor of tip shape }\end{array}$

Subscripts

$$
\begin{array}{lll}
i & : & \text { initial } \\
r & : & \text { residual } \\
L & : & \text { limit }
\end{array}
$$

\section{Introduction}

Space debris population has been constantly increasing since the beginning of space development. Conventional measures to mitigate the current debris situation are insufficient and active debris removal (ADR) methods are required. It is thought to be necessary to remove 5 large debris per year to maintain the current quantity. ${ }^{1)}$

The Japan Aerospace Exploration Agency (JAXA) is developing an ADR satellite using an electro-dynamic tether (EDT) system. Since most debris are not controlled in attitude and do not have a capture handle, a harpoon is a possible way of attaching the EDT; it does not require the debris removal satellite to have high precision attitude control.

The purpose of this study was to investigate different harpoon tips and their result on perforation. The target used was a $3 \mathrm{~mm}$ thick plate of 2024-T3 aluminum alloy, which replicated the surface of an H-IIA second stage. There are previous studies related to the perforation of an aluminum plate by a rod-like projectile, ${ }^{2-6)}$ but they focused on the behavior of aluminum. The present study has focused on the tip shapes of the projectiles, evaluating six design variations.

\section{Experimental Setup}

The experimental setup is shown in Fig. 1. A projectile and its sabot were accelerated by a powder gun and were separated by a sabot stopper. Then, the projectile impacted the target plate. The projectile velocity was calculated by using a high-speed camera to measure the number of pixels of the projectile's movement between frames.

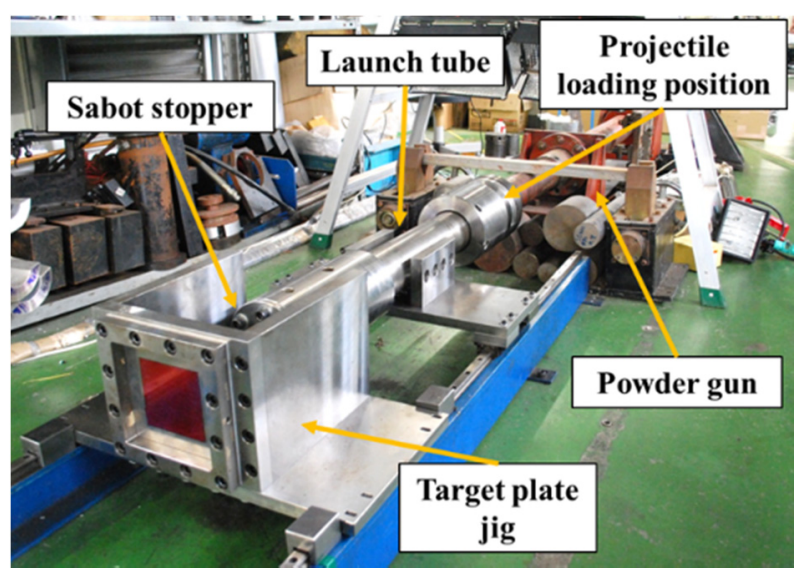

Fig. 1. Experimental setup. 


\section{Experiment}

\subsection{Targets and projectiles}

Specifications of the target plate are shown in Table 1. Generally, A2219-T87 is used as a material for rocket structure, but it cannot be easily obtained. Therefore A2024-T3 has been chosen as a material that has similar mechanical properties to A2219-T87. Both sets mechanical properties are shown in Table 2.

Projectiles were made of S45C carbon steel. Tip shapes were flat, flat 3 , cone, puncher 0 , puncher 2 and puncher 4 . The specifications of the projectiles are shown in Table 3 and each tip shape is shown in Fig. 2.

Table 1. Specifications of the target plate.

\begin{tabular}{|c|c|}
\hline Size $[\mathrm{mm}]$ & $200 * 200 * 3 \mathrm{t}$ \\
\hline Mass $[\mathrm{g}]$ & 320 \\
\hline
\end{tabular}

Table 2. Mechanical properties of A2024-T3 and A2219-T87.7)

\begin{tabular}{|c|c|c|}
\hline & A2024-T3 & A2219-T87 \\
\hline Ultimate tensile strength [MPa] & 485 & 475 \\
\hline Tensile yield strength [MPa] & 345 & 395 \\
\hline
\end{tabular}

Table 3. Specifications of the projectiles

\begin{tabular}{|c|c|}
\hline Diameter [mm] & 20 \\
\hline Length [mm] & 100 \\
\hline Mass [g] & 200 \\
\hline
\end{tabular}
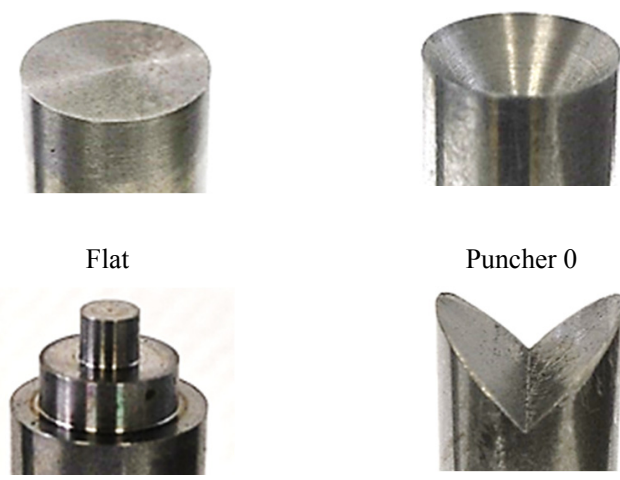

Puncher 0
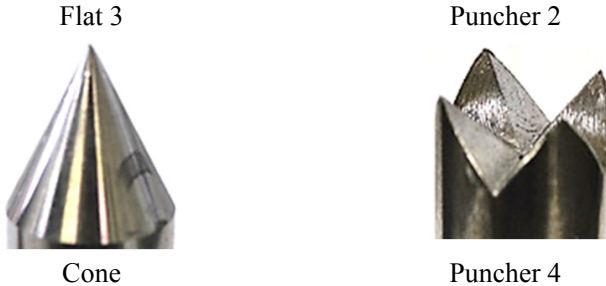

Fig. 2. The tip shapes of projectiles.

\subsection{Evaluation indexes}

An ideal harpoon for debris capture will perforate at a low velocity and thereby consume less kinetic energy. Thus, we set the following three evaluation indexes.

(1) Residual and initial velocity of the projectile

(2) Absorbed and impact energy of the projectile

(3) Penetration length of the projectile when it does not perforate the target plate

\section{Experimental Results}

Perforation holes created by the six types of projectiles are shown in Fig. 3; SN means Specimen Number. Perforation holes by flat, puncher 0 , puncher 2 and puncher 4 type projectiles were circular; the holes produced by flat and puncher 0 type projectiles were regular. Holes produced by flat 3 and cone type projectiles exhibited flower petals shaped holes.

Experimental results are shown in Table 4.

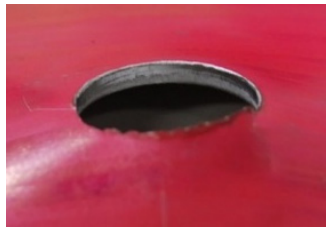

Flat, SN-016

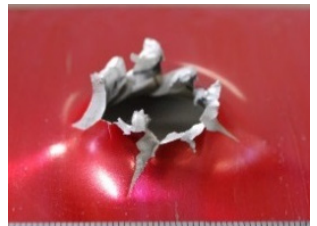

Cone, SN-018

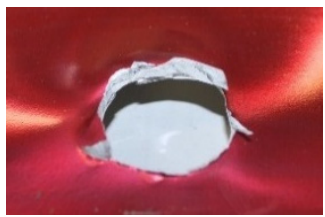

Puncher 2, SN-025

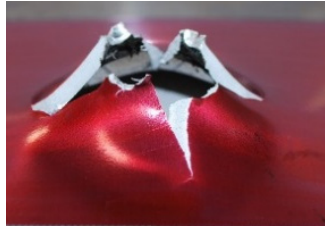

Flat 3, SN-024
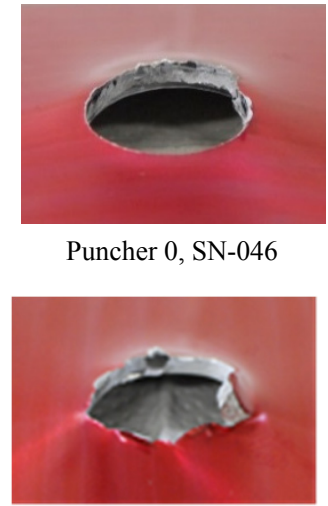

Puncher 4, SN-077
Puncher 0, SN-046

Fig. 3. Perforation holes.

\section{Discussion}

5.1. J. P. Lambert's formula and modification factor To analyze the data, we used J. P. Lambert's formula: ${ }^{8)}$

$$
\left.\begin{array}{c}
V_{L}=M U\left(\frac{L}{D}\right)^{0.15} \sqrt{\frac{f(Z) D^{3}}{W}} \\
V_{r}=0 \quad\left(0<V_{i}<V_{L}\right) \\
V_{r}=a\left(V_{i}^{P}-V_{L}^{P}\right)^{1 / P} \quad\left(V_{L}<V_{i}\right)
\end{array}\right\}
$$

where

$$
\begin{aligned}
& Z=\frac{T}{D}(\sec \theta)^{3 / 4} \\
& f(Z)=Z+e^{-Z}-1 \\
& a=\frac{W}{W+m / 3} \\
& m=\frac{\rho}{4} \pi D^{3} Z \\
& P=2+Z / 3 \\
& U=1750 \text { (Aluminum) }
\end{aligned}
$$


Table 4. Experimental results.

\begin{tabular}{|c|c|c|c|c|c|c|c|}
\hline $\begin{array}{l}\text { Specimen } \\
\text { Number }\end{array}$ & Type & Mass $[\mathrm{g}]$ & $\begin{array}{c}\text { Initial } \\
\text { velocity } \\
{[\mathrm{m} / \mathrm{s}]} \\
\end{array}$ & $\begin{array}{c}\text { Residual } \\
\text { velocity } \\
{[\mathrm{m} / \mathrm{s}]} \\
\end{array}$ & $\begin{array}{c}\text { Impact } \\
\text { energy }[\mathrm{J}]\end{array}$ & $\begin{array}{l}\text { Absorbed } \\
\text { energy [J] }\end{array}$ & $\begin{array}{c}\text { Penetration } \\
{[\mathrm{mm}]}\end{array}$ \\
\hline 014 & \multirow{4}{*}{ Flat } & 204.6 & 66.7 & 0.0 & 455.1 & 455.1 & 22 \\
\hline 016 & & 204.7 & 77.2 & 31.6 & 610.0 & 507.8 & - \\
\hline 045 & & 199.2 & 83.8 & 43.6 & 699.4 & 510.1 & - \\
\hline 069 & & 200.2 & 90.2 & 57.3 & 814.4 & 485.8 & - \\
\hline 021 & \multirow{4}{*}{ Flat 3} & 196 & 51.0 & 0.0 & 254.9 & 254.9 & 0 \\
\hline 024 & & 198.8 & 75.0 & 22.9 & 559.1 & 507.0 & - \\
\hline 029 & & 198.8 & 93.8 & 59.4 & 874.6 & 523.8 & - \\
\hline 075 & & 199.3 & 78.1 & 27.0 & 607.8 & 535.2 & - \\
\hline 017 & \multirow{7}{*}{ Cone } & 199.5 & 62.9 & 0.0 & 394.7 & 394.7 & 56 \\
\hline 018 & & 199.9 & 74.2 & 31.3 & 550.3 & 452.4 & - \\
\hline 019 & & 199.8 & 58.1 & 0.0 & 337.2 & 337.2 & 46 \\
\hline 020 & & 199.6 & 69.9 & 17.6 & 487.6 & 456.7 & - \\
\hline 022 & & 200.2 & 90.8 & 61.3 & 825.3 & 449.1 & - \\
\hline 023 & & 199.5 & 88.9 & 60.5 & 788.3 & 423.2 & - \\
\hline 070 & & 199.6 & 94.2 & 67.6 & 885.6 & 429.5 & - \\
\hline 046 & \multirow{6}{*}{ Puncher 0} & 200.8 & 75.4 & 17.2 & 570.8 & 541.1 & - \\
\hline 074 & & 200.6 & 90.4 & 65.5 & 819.7 & 389.4 & - \\
\hline 078 & & 200.1 & 47.4 & 0.0 & 224.8 & 224.8 & 0 \\
\hline 080 & & 200.4 & 86.1 & 56.6 & 742.8 & 421.8 & - \\
\hline 081 & & 199.6 & 65.5 & 6.1 & 428.2 & 424.5 & - \\
\hline 082 & & 200.2 & 81.0 & 41.2 & 656.8 & 486.8 & - \\
\hline 025 & \multirow{7}{*}{ Puncher 2} & 200.1 & 90.7 & 64.4 & 823.1 & 408.1 & - \\
\hline 026 & & 198.9 & 63.6 & 0.0 & 402.3 & 402.3 & 91 \\
\hline 027 & & 198.3 & 93.3 & 68.0 & 863.1 & 404.6 & - \\
\hline 028 & & 198.9 & 50.5 & 0.0 & 253.6 & 253.6 & 0 \\
\hline 071 & & 200 & 44.3 & 0.0 & 196.2 & 196.2 & 0 \\
\hline 073 & & 200 & 86.4 & 60.3 & 746.5 & 382.9 & - \\
\hline 076 & & 200 & 83.9 & 55.3 & 703.9 & 398.1 & - \\
\hline 038 & \multirow{2}{*}{ Puncher 4} & 198.9 & 87.2 & 40.7 & 756.2 & 591.5 & - \\
\hline 077 & & 200.2 & 74.0 & 23.8 & 548.1 & 491.4 & - \\
\hline
\end{tabular}

When a long rod penetrator strikes an aluminum target plate, this formula provides the limit velocity $V_{L}$ for perforation, and the residual velocity $V_{r}$. We added a modification factor, $M$, into this formula to consider the tip shape effects, and calculated it from the experimental conditions and data. The results are shown in Tables 5 and 6 . They show that flat and puncher 0 tips have the same value and the puncher 2 tip has the smallest modification factor.

\begin{tabular}{|} 
Table 5. & Experimental conditions. \\
\begin{tabular}{|cc|c|}
\hline$W$ & {$[\mathrm{~g}]$} & 200 \\
\hline$L$ & {$[\mathrm{~cm}]$} & 10 \\
\hline$D$ & {$[\mathrm{~cm}]$} & 2 \\
\hline$T$ & {$[\mathrm{~cm}]$} & 0.3 \\
\hline$\rho$ & {$\left[\mathrm{g} / \mathrm{cm}^{3}\right]$} & 2.7 \\
\hline$\theta$ & {$[\mathrm{deg}]$.} & 0 \\
\hline
\end{tabular}
\end{tabular}

Table 6. Results of calculations.

\begin{tabular}{|c|c|c|}
\hline Type & Modification factor & Limit velocity $[\mathrm{m} / \mathrm{s}]$ \\
\hline \hline Flat & 1.54 & 71.0 \\
\hline Flat 3 & 1.57 & 72.4 \\
\hline Cone & 1.46 & 67.3 \\
\hline Puncher 0 & 1.54 & 71.0 \\
\hline Puncher 2 & 1.39 & 64.1 \\
\hline Puncher 4 & 1.55 & 71.5 \\
\hline
\end{tabular}




\subsection{Residual and initial velocity}

The results of the residual and initial velocity are shown in Fig. 4. In this figure, "TV" means theoretical value calculated by J. P. Lambert's formula with the tip shape modification factor. Residual velocity increased proportionally to the initial velocity. The curves of flat and puncher 0 tips overlap each other because their tip shape modification factors have the same value. The residual velocity of the puncher 2 type projectile is higher than that of the others.

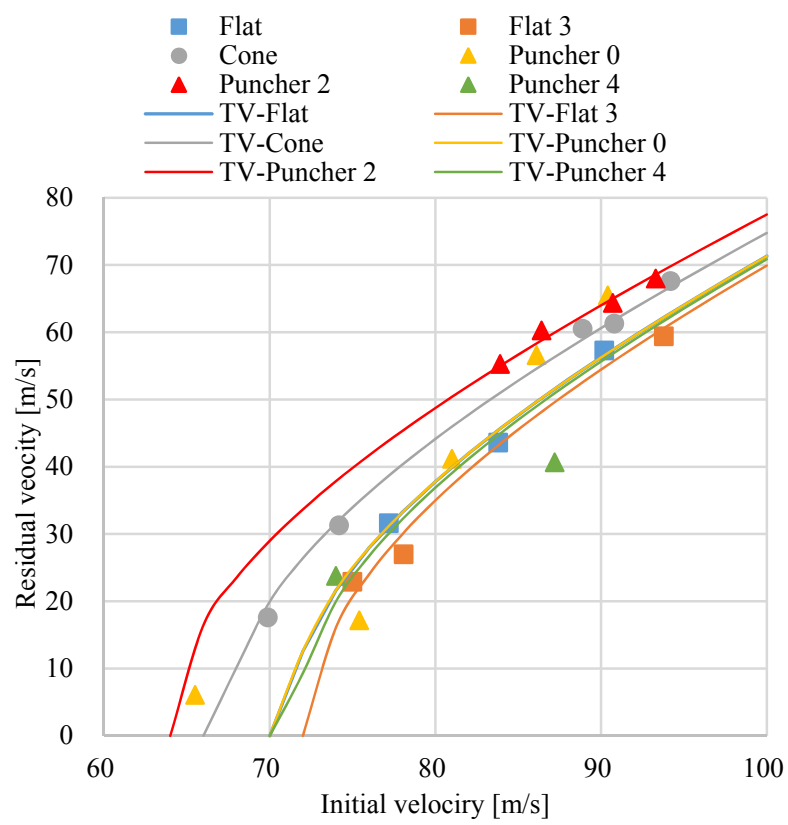

Fig. 4. Residual and initial velocity.

\subsection{Absorbed and impact energy}

The results of absorbed and impact energy are shown in Fig. 5. For the flat, flat 3, cone and puncher 2 types, the absorbed energy was constant with respect to the initial velocity. The puncher 2 type was the most efficient shape because the absorbed energy was lower than that of the others. Conversely, the absorbed energy of the puncher 0 type increased to $550 \mathrm{~J}$ and decreased rapidly, therefore the theoretical curve does not fit the data. The curve of puncher 4 also does not fit the data; two hypotheses are considered for this: The first is that the perforation holes were irregularly large; the holes of SN-082 and SN-038 are shown in Fig. 6. These holes were not circular and it is thought that the formation of such holes has led to increased absorbed energy. The second is that the target plate was not fixed properly. Twelve bolts were used to fix the target plate to a jig in these experiments. If the bolts had not been fastened correctly, the sides of the plate could have moved towards the center at the moment of impact, and more impact energy could have been absorbed.

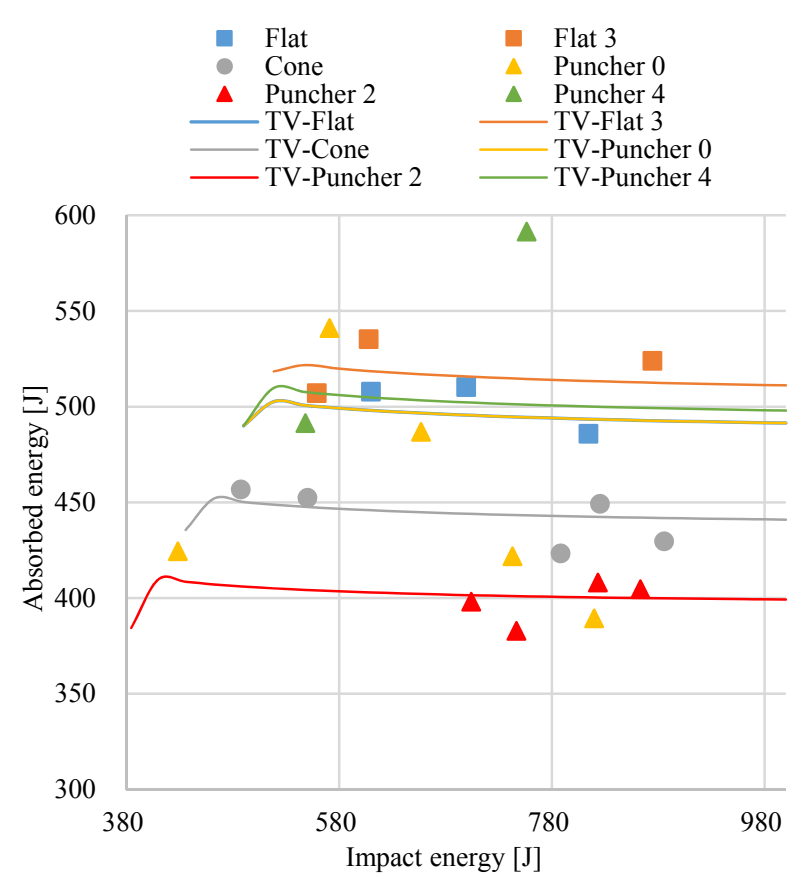

Fig. 5. Absorbed and impact energy.

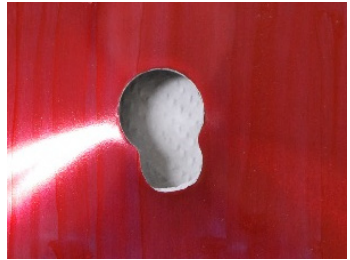

Puncher 0, SN-082

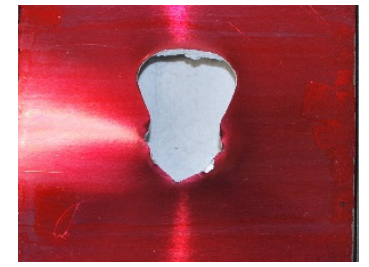

Puncher 4, SN-038
Fig. 6. Irregular perforation holes.

\subsection{Penetration length}

Results of the penetration length and initial velocity are shown in Fig. 7. The length and mass of all harpoons were the same, so the difference in penetration length was caused by the difference in tip shape. The figure shows that the puncher 2 projectile was superior to the flat, flat 3 and cone type projectiles and it agrees with the results of absorbed and impact energy. In addition, the limit velocity of these projectiles was $50-65 \mathrm{~m} / \mathrm{s}$, thus the impact velocity should be more than $70 \mathrm{~m} / \mathrm{s}$.

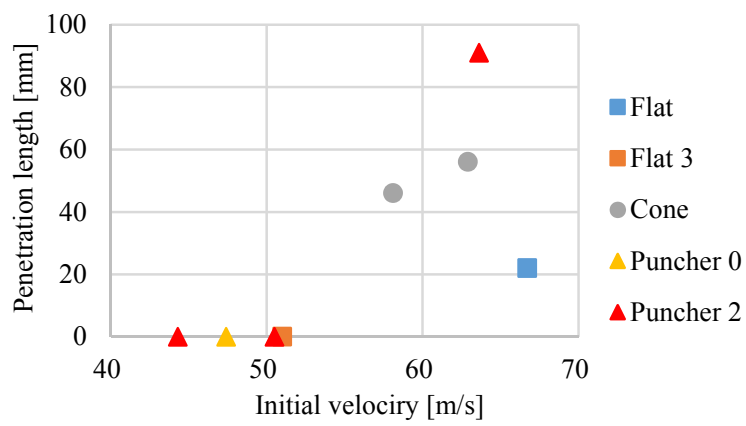

Fig. 7. Penetration length and initial velocity. 


\section{Conclusion}

In conclusion, the perforation properties of harpoons with a range of different tips were obtained and experimental data showed that the puncher 2 type was superior to others for perforation. We analyzed the data using Lambert's formula with a tip shape modification factor, and the theoretical values of flat, flat 3, cone, and puncher 2 types fitted the experimental data.

If a harpoon is used against a quick tumbling target in space, the incidence angle may not be 0 degrees. So further experiments simulating oblique incidence angles are required.

\section{References}

1) Liou, J. C.: An Update on LEO Environment Remediation with Active Debris Removal, Orbital Debris Quarterly News, 15 (2011), pp. 4-6.

2) Piekutowski, A. J., Forrestal, M. J., Poormon, K. L. and Warren, T. L.: Perforation of Aluminum Plates with Ogive-nose Steel Rods at Normal and Oblique Impacts, International Journal of Impact Engineering, 18 (1996), pp. 877-887.

3) Gupta, N. K., Iqubal, M. A. and Sekhon, G. S.: Effect of Projectile Nose Shape, Impact Velocity and Target Thickness on Deformation Behavior of Aluminum Plates, International Journal of Solids and Structures, 44 (2007), pp. 3411-3439.

4) Grytten, F., Børvik, T., Hopperstad, O. S. and Langseth, M.: low Velocity Perforation of AA5083-H116 Aluminum Plates, International Journal of Impact Engineering, 36 (2009), pp. 597-610.

5) Rodríguez-Martínez, J. A., Rusinek, A. and Arias, A.: Thermo-viscoplastic Behavior of 2024-T3 Aluminum Sheets Subjected to Low Velocity Perforation at Different Temperatures, Thin-Walled Structures, 49 (2011), pp. 819-832.

6) Iqubal, M. A., Khan, S. H., Ansari, R. and Gupta, N. K.: Experimental and Numerical Studies of Double-nosed Projectile Impact on Aluminum Plates, International Journal of Impact Engineering, 54 (2013), pp. 232-245.

7) Lampman, S. R.: Fatigue and fracture, ASM International, Ohio, 1996, pp.788-789.

8) Lambert, J. P. and Ringers, B.E.: Standardization of Terminal Ballistic Testing, Data Storage and Retrieval, AD-A056366 (1978). 